\author{
ARTIGO \\ do https://doi.org/10.22481/rpe.v16i43.6630
}

\title{
A LITERATURA DE CORDEL: UM RECURSO INOVADOR NAS AULAS DE ENSINO RELIGIOSO
}

\author{
CORDEL LITERATURE: AN INNOVATIVE RESOURCE IN RELIGIOUS STUDIES \\ LESSONS \\ LITERATURA DE CORDEL: UN RECURSO INNOVADOR EN CLASES DE \\ EDUCACIÓN RELIGIOSA
}

Paula Marques Pessoa de Aquino Universidade Federal da Paraíba - Brasil

\author{
Vitória da Cunha Ferreira \\ Universidade Federal da Paraíba - Brasil \\ Lusival Antonio Barcellos \\ Universidade Federal da Paraíba - Brasil
}

\begin{abstract}
Resumo: A literatura de cordel é recurso inovador capaz de propiciar aos docentes, sobretudo, de Ensino Religioso (ER), um ótimo resultado educacional para empolgar e instigar os estudantes nas aulas síncronas e assíncronas. Esse gênero literário como experimento pedagógico, ainda é pouco utilizado nas escolas. Portanto, o presente artigo trata-se de uma pesquisa exploratória que utilizou da entrevista semiestruturada na coleta de dados numa amostra que contou com 08 educadores de ER. Através da Análise de Conteúdo de Bardin (2020), foi constatado que todos os professores conheciam a Literatura de Cordel, dos quais seis afirmaram sua utilização como recurso pedagógico. Sobre sua inserção no ER, cinco participantes declararam que o emprego deste gênero na sala de aula era formidável devido sua pluralidade e diversidade de temas. Concluindo-se assim que a Literatura de Cordel, por sua acessibilidade oportuniza ao estudante um ensino inovador, lúdico e contextualizado.
\end{abstract}

Palavras-chave: Literatura de Cordel. Recurso Pedagógico. Ensino Religioso.

Abstract: Cordel literature is an innovative resource capable of providing teachers, above all, of Religious Education (ER), a great educational result to excite and instigate students in synchronous and asynchronous classes. This literary genre as a pedagogical experiment, is still rarely in schools. Therefore, this article is an exploratory research that used the semi-structured interview to collect data in a sample that included 08 RE educators. Through Bardin's Content Analysis (2020), it was found that all teachers knew Cordel Literature, of which six affirmed its use as a pedagogical resource. Regarding their insertion in the ER, five participants declared that the use of this genre in the classroom was formidable due to its plurality and diversity of themes. Thus, concluding that Cordel Literature, due to its accessibility, provides the student with an innovative, playful and contextualized teaching.

Keywords: Cordel Literature. Pedagogical Resource. Religious Education. 
Resumen: La literatura de Cordel es un recurso innovador capaz de proporcionar a los profesores, especialmente de Educación Religiosa (ER), un excelente resultado educativo para excitar e instigar a los estudiantes en clases sincrónicas y asincrónicas. Este género literario como experimento pedagógico es todavía poco utilizado en las escuelas. Por lo tanto, este artículo es un estudio exploratorio que utilizó la entrevista semiestructurada para recoger datos en una muestra que incluía 08 educadores de la ER. A través del Análisis de Contenido de Bardin (2020), se encontró que todos los profesores estaban familiarizados con la literatura de Cordel, seis de los cuales afirmaron su uso como recurso pedagógico. Sobre su inserción en la ER, cinco participantes declararon que el empleo de este género en el aula era formidable debido a su pluralidad y diversidad de temas. La conclusión es que la literatura de Cordel, por su accesibilidad, proporciona al estudiante una enseñanza innovadora, lúdica y contextualizada.

Palabras clave: Literatura de Cordel. Recurso pedagógico. Educación religiosa.

\section{Introdução}

A cultura, especialmente a brasileira é rica em suas manifestações, de diferentes tipos e formas ela está localizada no centro da existência humana, e ao mesmo tempo em que auxilia o homem a inserir-se na sociedade de modo criativo e eficaz, esta, é capaz de mediar e interceder também nos processos de ensino-aprendizagem. É por este e outros tantos motivos que a Literatura de Cordel, como cultura popular brasileira inserida no Nordeste, perdura até hoje, resistindo e se adaptando as novidades da contemporaneidade.

A literatura de cordel é escrita de forma rimada, ilustrada com xilogravuras, técnica de gravura na qual utiliza a madeira como matriz e há a impressão da imagem sobre o papel, tecido, ou outro suporte adequado. De forma mais tradicional, os autores recitam os versos acompanhados por algum instrumento de corda, a fim de conquistarem possíveis compradores (MAXADO, 1980).

Desde o princípio, o cordel obteve sucesso, não apenas em virtude da acessibilidade e menor preço, mas, também, pelo tom humorístico das histórias contadas nos versos ou prosas, e pela possibilidade de retratar fatos da vida cotidiana da cidade ou da região. De acordo com Silva (2016), o cordel aborda diferentes conteúdos, entre eles questões humanas, a sociedade patriarcal, o capitalismo, o cangaço, romance, folclore, política, o sagrado, divino, desvios de condutas, castigos, crenças e descrenças em Deus, entre outros.

O cordel diz respeito a um tipo de cultura que conta com textos rimados e xilogravuras, onde composto de criatividade e inspiração, os cordelistas não hesitam em inventar versos no improviso, para tratarem determinadas temáticas, dado que, ao ser utilizado como porta voz de informações, tem ação revolucionária, tornando-se útil como recurso educacional (CASTRO; 
COSTA, 2015). No que concerne o contexto escolar, para que o ensinamento de fato aconteça, o professor pode criar e inventar, fazendo uso de meios diversos para alcançar seu objetivo (MORAN, 2000).

Partindo dessa asserção, o profissional de ER, assim como de outras áreas do conhecimento (BRASIL, 2019), pode utilizar o cordel de diversas formas, desde maneiras mais simples como leituras em conjunto, até a criação dos seus próprios folhetos de acordo com o que está sendo apresentado em sala de aula (MARINHO; PINHEIRO, 2012).

Com base nessas indicações, foi realizada uma pesquisa exploratória com o objetivo de analisar a percepção dos professores de ER frente à utilização da literatura de cordel como recurso pedagógico e sua contribuição para a educação. Para fins didáticos, estruturou-se o trabalho em seis tópicos: Um breve histórico acerca da literatura de cordel, as contribuições do cordel como recurso pedagógico, os embricamentos do cordel dentro do ER, método de pesquisa, resultados e conclusão.

A partir da transcrição literal das entrevistas, iniciou-se uma análise de conteúdo, na qual foram identificadas as falas comuns a todas as entrevistas e levantadas as frequências dessas falas, buscando ainda identificar argumentos, explicações ou contradições que melhor revelassem as percepções desses profissionais sobre a literatura de cordel.

O presente artigo contou-se com a colaboração de 08 professores de ER, sendo 04 do sexo masculino e 04 do sexo feminino com idades entre 29 e 76 anos, residentes na cidade de João Pessoa, Paraíba.

\section{Breve Histórico}

No Brasil, a literatura de cordel está intrinsicamente ligada ao desejo de comunicação, em relação a sua origem no contexto brasileiro, não há um consenso entre os estudiosos, embora a hipótese mais aceita seja que Portugal tenha tido relevante influência, especialmente os lusitanos, que cantavam em rimas e em grupos os acontecimentos (DIÉGUES JÚNIOR, 1975). Considerando esta afirmativa, Haurélio (2010) declara, que este gênero literário chegou ao Brasil há muito tempo atrás, especificadamente antes do século XX.

Nesta conjuntura, os nordestinos com astúcia abancaram o produto português e aprimoraram ao lugar, tendo como alguns pioneiros Silvino Pirauá Lima (1849-1913), repentista, criador da cantoria moderna, introdutor do romance em versos, Leandro Gomes de Barros (18651918) o primeiro a fundar o cordel como texto literário, Francisco Chagas Batista (1882-1930) 
que compilou junto a outros cordelistas a primeira coletânea do gênero, dentre outros, fazendo com que por meio de sua dimensão expressiva e histórica o cordel seja visto como um anunciador de transformações (MENESES, 2019).

Face aos argumentos apresentados, a Academia Brasileira de Literatura de Cordel (ABLC) fundada em 1988 no Rio de Janeiro, solicitou por meio do Centro de Folclore e Cultura Popular (CNFCP) que a Literatura de Cordel fosse considerada patrimônio imaterial do Brasil ao Instituto do Patrimônio Histórico e Artístico Nacional (IPHAN) em 2009, enfatizando a cultura popular e a arte, sob o decreto de $\mathrm{n}^{\mathrm{o}} 3.551$, o qual representou um grande passo para o reconhecimento deste gênero como proclamador de conhecimento (HEINICH, 2009; NOGUEIRA, 2019).

A literatura de cordel é arte e poesia, música e narrativa, sua relevância não se limita a uma determinada época, mas é atemporal, haja vista que apesar de ser produzido de maneira simples, seu folheto pode ocasionar grandes mudanças, pois não leva ao leitor apenas palavras que rimam, mas conhecimento em forma de poesia, que deve ser difundido entre as diversas áreas do conhecimento (MOREIRA et al, 2019). Levando essa contribuição para a sala de aula, a interlocução do cordel como experimento educacional, torna-se um facilitador eficiente para possibilitar um processo de ensino-aprendizagem. (FONSECA; FONSÊCA, 2008).

\section{Literatura de Cordel como recurso pedagógico}

Segundo Morin (2002), o profissional ao exercer seu papel de educador deve contribuir para que o indivíduo aprenda; não só conhecimentos referentes às disciplinas, mas seja um sujeito crítico e torne-se um digno cidadão. Neste contexto, destaca-se que a educação vive em constante desenvolvimento. No ocidente, esta era caracterizada apenas pela transmissão de conteúdo, em que o docente era o responsável em transmitir uma gama de informações e os discentes, absorviam tudo sem qualquer modificação, a este tipo de educação, Paulo Freire (2020) nomeou de bancária, característica primordial do modelo educativo tradicional, que era mecanicista e tecnicista. Nesta modalidade, o estudante era passivo e incapaz de construir conhecimento, por ser apenas um recebedor e não um construtor de saberes (BORDENAVE; PEREIRA, 2007).

No entanto, o ato de educar e aprender transcende esta concepção, cujo modo é incapaz de permitir que o estudante seja ativo no seu processo de aprendizagem (FIGUEIREDO; RODRIGUES-NETO; LEITE, 2010). Dessa forma, ao entender que o ensino não acontece sob um depósito de informações, mas trata-se de um processo interativo em que educador e educando 
aprendem em conjunto, o professor é impulsionado a indagar-se sobre esta metodologia tradicional e motivado a buscar meios de tornar o estudante o grande protagonista da história (STACCIARINI; ESPERIDIÃO, 1999).

A partir dessa premissa, a aplicação da Literatura de Cordel mostra-se como um meio, pois propicia ao professor contar com uma ferramenta capaz de trazer nova roupagem ao conteúdo, potencializando a autonomia dos estudantes por meio da exploração de suas habilidades e competências (PEREIRA et al, 2014). Na prática pedagógica, a utilização deste gênero literário instiga a observação dos diversos acontecimentos sociais e ocasiona o surgimento e aprimoramento do olhar crítico do estudante. Além disso, o insere na cultura popular nordestina e estimula a leitura e a criatividade em sala de aula, haja vista que durante o contar das histórias o professor oferece aprendizado através do significado que o estudante atribui as rimas (SOUZA; FRANCISCO, 2017).

A linguagem simplória, rítmica e original, são elementos essenciais para motivação educacional, e embora alguns tenham a percepção de que o Cordel é insuficiente em sua aplicação nas escolas, o que se constata é que sua contribuição pode ser dada da alfabetização ao ensino superior (CASTRO; COSTA, 2015). Suas vastas possibilidades de temas presentes na região nordestina e no país como um todo, têm chamado à atenção dos docentes, que buscam meios interativos para ensinar, pois de acordo com que se argumenta Silva Filho (2009, p. 11) "[...] usando a literatura de cordel, o professor não estará somente usando o recurso pedagógico em si, como também valorizando aquela parte da cultura, que, mesmo vinda da Europa, ficou tão brasileira como o futebol".

Inúmeras são as formas de trabalho com o Cordel, basta que o professor acredite que este gênero tem potencial para lhe amparar na mediação e facilitação do conhecimento (MOREIRA et al, 2019). Nesse cenário, não só o aspecto rítmico do cordel é capaz de ser explorado no âmbito escolar, mas sua característica artística, onde o estudante além de declamar versos e rimas, ler e criar seus próprios cordéis, desenvolve seu imaginário, utilizando os desenhos de xilogravuras para expressar a aprendizagem (COSTA, 2017).

Face ao exposto, apesar do preconceito cravado na Literatura de Cordel, esta vem se desenvolvendo e encontrando seu espaço paulatinamente na sala de aula (COBIAN; COSTA; PINTO, 2011), local onde segundo Belisario e Albuquerque (2015), o professor tem a grande missão de motivar e propagar sua funcionalidade, apropriada para transmitir saberes e se adaptar a diversas áreas do conhecimento, inclusive a do ER. 


\section{A utilização da literatura de Cordel no Ensino Religioso}

Para Holmes (2016), o ER tem raízes muito antigas no território brasileiro, sua origem está atrelada ao período colonial, momento em que, ao chegar à nova terra, os portugueses buscavam impor a fé católica aos nativos. Tal afirmativa fica explicita a partir da celebração da primeira missa e da imposição de uma grande cruz de madeira no local, atos que buscavam chamar a atenção indígena para a estima e consideração frente à religião. Salvar aquele povo tido como "sem crença" tornou-se um relevante objetivo para os colonizadores, que buscavam não só propiciar a salvação, mas catequizá-los, visando posteriormente à exploração do seu trabalho, conhecimento e cultura.

Mais tarde, a Igreja Católica, a fim de continuar seu processo de doutrinação, criou um projeto educacional coordenado pelos Jesuítas, que contemplava tanto índios, como a elite colonial (RIBEIRO, 1982). Esse mesmo projeto foi substituído pelo Ratio Studiorum, sistematizado pela Companhia de Jesus. Na época, a relação entre Igreja e Estado era muito estreita, o que favorecia a propagação do cristianismo católico com facilidade (SANTOS, 2019). Segundo Ranquetat Junior (2007), a influência da Igreja era tanta, que a mesma tornou-se a religião oficial do império.

Nesse sentido, o ensino ofertado era indiferente à cultura e a religiosidade encontrada, pois se educava considerando a religião e não as religiões (FREITAS, 2018). Com o passar do tempo e a realização do Concílio Vaticano I, a relação entre Igreja e Estado foi se enfraquecendo, ademais o surgimento da República também contribuiu para este abrandamento, possibilitando o rompimento do privilégio direcionado ao ensino católico e abrindo espaço para um estado e educação baseada na laicidade (HOLMES, 2016).

Com essa Laicização, o ER foi eliminado das escolas, pois Rui Barbosa, assim como, os escolanovistas defendiam com afinco que o Estado Laico deveria excluí-lo de sua matriz educacional. Após essa supressão, somente com o governo de Getúlio Vargas e a criação do Ministério da Educação e Saúde Pública, o que hoje é chamado de Ministério da Educação (MEC) foi que este ensino foi reinserido nas escolas públicas do Brasil, mas com uma ressalva, o decreto instituído em 30 de Abril de 1931 de $\mathrm{n}^{\circ} 19.941$ o determinava como facultativo (HOLMES, 2016; MARIANO, 2003).

Ainda nesta perspectiva, na constituição de 16 de julho de 1934, atendendo as reivindicações da Igreja Católica, o ER foi reintroduzido, sendo desenvolvido de acordo com a confessionalidade do estudante, revelada pelos pais ou responsáveis. Em 1937, a Constituição de 10 de novembro subtraiu sua importância, alegando em seu artigo 133 que seria apenas uma 
complementação do processo educativo nas escolas primárias, secundárias e normais (HOLMES, 2016). Diante disso, é relevante salientar que no transcorrer desta história, as Leis de Diretrizes e Bases (LDB) exerceram um importante papel, pois demonstram nitidamente os pequenos avanços e reconhecimentos do ER ao longo do tempo (SANTOS, 2019).

Segundo Freitas (2018), na LDB de $n^{\circ} 4.024 / 61$ o ER era visto como facultativo e o estado não tinha obrigatoriedade nos cofres públicos. A lei 5.692/71, de 1971, limitou-se a repetir no Artigo $7^{\circ}$, o dispositivo da Constituição da República e a Emenda Constitucional no . 01/69, em que inclui o ER nos horários normais das escolas servindo de alicerce para uma proposta interconfessional. Em meio a essa trajetória e adentrando a constituição de 1988 a qual visava um ensino em que as igrejas eram responsáveis por designar os professores gratuitamente, o Fórum Nacional e Permanente do Ensino Religioso (FONAPER), criado em 1995, destacou-se ao organizar e subsidiar os esforços de professores, associações e pesquisadores afim de salvaguardar a identidade do ER como qualquer outra disciplina do currículo escolar.

A LDB de $\mathrm{n}^{\circ}$ 9.394, de 23 de dezembro do ano de 1996, definia um ensino de matrícula facultativa, sem ônus para os cofres públicos e de caráter confessional e/ou interconfessional, sendo que as escolas deveriam assegurar práticas alternativas caso o estudante não escolhesse a disciplina predita (BRASIL, 1996). Nesse momento, a Conferência Nacional dos Bispos do Brasil (CNBB), o FONAPER e a Associação de Professores de Ensino Religioso (ASPER) se uniram e enviaram uma carta solicitando das autoridades políticas que direcionassem atenção ao ER, na futura Lei de Diretrizes e Bases.

Muitas foram às tentativas das instituições, mas, sobretudo, do FONAPER, junto ao Conselho Nacional de Educação (CNE) em solicitar o reconhecimento do ER como componente curricular obrigatório na educação básica. Logo após a homologação da LDB n 9.394/96, o Ministério da Educação lança os Parâmetros Curriculares Nacionais (PCN) de todas as áreas de conhecimento, tendo uma única exceção: a do ER. Foi mérito do FONAPER publicar, num mutirão de muitos voluntários, os Parâmetros Nacionais do Ensino Religioso (PCNER), uma grande conquista, que por mais de duas décadas foi referência para os docentes e para formação básica do cidadão (CARON, 1998).

No entanto, um largo passo dado para o desenvolvimento que as instituições, órgãos e movimentos tanto sonhavam, estaria na nova redação do Art. 33 da Lei 9394/96. Lei nº 9475/97 (BRASIL, 1997) que oportunizou a condecoração do ER como disciplina integrativa na formação do indivíduo, colocando suas aulas em horários normais, garantindo o respeito à pluralidade religiosa do país e excluindo a possibilidade de um educar prosélito (JUNQUEIRA, 2002; 
OLIVEIRA, 2005). Em 2010, a Resolução CNE/CEB nº 7, que aborda as Diretrizes Curriculares Nacionais para o Ensino Fundamental de 9 (nove) anos, institui o ER como uma das cinco áreas de conhecimento:

Art. 15 Os componentes curriculares obrigatórios do Ensino Fundamental serão assim organizados em relação às áreas de conhecimento:

I - Linguagens:

a) Língua Portuguesa;

b) Língua Materna, para populações indígenas;

c) Língua Estrangeira moderna;

d) Arte; e

e) Educação Física;

II - Matemática;

III - Ciências da Natureza;

IV - Ciências Humanas:

a) História;

b) Geografia;

V - Ensino Religioso. (BRASIL, 2010, grifo nosso).

De acordo com Amaral, Oliveira e Souza (2017), o MEC na terceira versão da Base Nacional Comum Curricular (BNCC) excluiu a área do ER. Sequencialmente, o FONAPER, a Coordenação dos cursos de graduação em Ciências das Religiões da Universidade Federal da Paraíba, a Coordenação da área 44 de Ciências da Religião e Teologia da Capes, várias direções das escolas públicas e de sindicatos, grupos de pesquisas, diversas instituições, na Paraíba, Espírito Santo, Minas Gerais, Amazonas e Santa Catariana, estiveram presentes nas audiências públicas promovidas pelos membros da Comissão Bicameral, do Conselho Nacional de Educação e deram fundamental contribuição, a fim de incluir o ER novamente nas páginas da base supracitada (FREITAS, 2018).

Em outubro de 2019, o Parecer CNE/CEB nº 8, altera o artigo 15 da Resolução CNE/CEB nº 7 e dá nova redação ao ER, que deixa de ser Área de Conhecimento e passa a ser Componente Curricular:

Art. 15 Os componentes curriculares obrigatórios do Ensino Fundamental serão assim organizados em relação às áreas de conhecimento:

I - Linguagens:

a) Língua Portuguesa;

b) Língua Materna, para populações indígenas;

c) Língua Estrangeira moderna;

d) Arte; e

e) Educação Física;

II - Matemática;

III - Ciências da Natureza;

IV - Ciências Humanas:

a) História;

b) Geografia;

c) Ensino Religioso. (BRASIL, 2019, grifo nosso). 
Dessa forma, a trajetória desse Componente Curricular é marcado por muitos e sucessivas resistências, as quais são superados graças à persistência do FONAPER, da Associação Nacional de Pós-graduação e Pesquisa em Teologia e Ciências da Religião (ANPTECRE), da Rede Nacional das Licenciaturas em Ensino Religioso (RELER), dos Cursos de Graduação em Ciência(s) da(s) Religião(ões), das Associações de professores e inter-religiosa com a Associação Inter-religiosa de Educação (ASSINTEC), dentre outras instituições e pessoas que querem que seja assegurado o que está prescrito na legislação sobre o ER.

Todavia, apesar dos avanços existentes, na contemporaneidade, o docente que ministra o Ensino Religioso na educação básica, passa por uma tarefa desafiadora, na qual é provocado a encontrar metodologias para desenvolver de maneira lúdica, séria e comprometida, um ensino em que o estudante possa respeitar as diferenças, as filosofias de vidas, a diversidade religiosa e cultural (OLIVEIRA et al, 2019).

Nesse interim, ao levar para sala de aula práticas didáticas e pedagógicas diversas, Junqueira (2002) destaca que nesta situação é indubitavelmente necessário usar elementos que realce a comunicação e a interação entre discentes, mostrando-se o cordel uma ótima opção, pois nele a palavra propaga saberes, gera convivência e tem capacidade de transformação. Outrossim, este gênero literário pode ser incluído nas mais diversas áreas, pois a seu respeito Adeliano Brandão afirmava que "[...] nada lhe é estranho" (MENESES, 2019).

Considerando o ensejo, o professor de Ensino Religioso tem a liberdade de utilizar maneiras atraentes, que não deixe a aprendizagem cansativa, mas provocante por meio da Literatura de Cordel, que se coloca de modo aberto para trabalhar os mais variados temas, inclusive o que é proposto pela Proposta Curricular da Paraíba (PARAÍBA, 2019), a saber, identidade e alteridade, manifestações religiosas, crenças e filosofias de vida, as quais se tratam de unidades temáticas propostas pela BNCC (BRASIL, 2017) no território paraibano.

Alguns métodos podem ser qualificados como potencializadores no processo de inserção do cordel na sala de aula, desde a introdução ao conteúdo trabalhado a partir de levantamentos de córdeis que abordariam a temática desejada, como uma provocação para os discentes executem suas próprias criações e até realizarem exposição de xilogravuras. (LARCERDA; MENEZES NETO, 2010; MARINHO; PINHEIRO, 2012). Fazendo uso deste recurso, o profissional contemplará ao estudante algumas vantagens, como reflexão através do lúdico, presença ativa no próprio processo de ensino-aprendizagem, além de ajudar o estudante na construção do conhecimento a instigar seu olhar crítico (SILVA et al, 2010). Assim, o professor estará utilizando um produto nordestino para propagar a cultura de paz, a diversidade cultural, os 
valores e os princípios universais, os direitos humanos tão importante nos dias hoje, onde à intolerância religiosa e a homofobia tem ceifado muitas vidas (MENESES, 2019).

\section{Garimpando o Cordel}

O presente artigo alude a um estudo exploratório, contou-se com a colaboração de 08 professores de Ensino Religioso, sendo 04 do sexo masculino e 04 do sexo feminino com idades entre 29 e 76 anos, residentes na cidade de João Pessoa, Paraíba. Ao obter a anuência dos docentes através do Termo de Consentimento Livre e Esclarecido (TCLE), os referidos participantes responderam de forma online a uma entrevista semiestruturada, constituída por perguntas sócio demográficas a fim de traçar o perfil da amostra e indagações como: "O que você entende por Literatura de Cordel?"; "Você acha que é possível utilizar a Literatura de Cordel como método pedagógico de ensino religioso?", bem como se "Você já utilizou a Literatura de Cordel no processo de ensino-aprendizagem?", objetivando saber a respeito da percepção dos mesmos frente à aplicação da Literatura de Cordel no Ensino Religioso. Para a análise dos dados foi utilizada a técnica de Análise de Conteúdo de Bardin (2020), que é capaz de possibilitar ao pesquisador a realização de interpretações e inferências com base nas informações coletadas.

\section{Resultados e discussões}

Todos os entrevistados responderam positivamente sobre conhecer a literatura de cordel, além de corroborar pelo menos, minimamente, com seu processo criativo-histórico-popular, como podemos observar na fala do entrevistado número 3, "Na minha visão é um poema e/ou uma poesia popular sobre determinado tema que apresenta certa profundidade e conhecimento por parte de seus autores, que se dedicam com exclusividade na sua escrita em formas de rima. As quais são transformadas em pequenos mini livros." E na fala do entrevistado número 4, "Historicamente, eram os pequenos livretos vendidos nas feiras que ficavam suspensos e expostos em cordas, daí o nome. Sai livros que geralmente contam causos e histórias nordestinas de forma poética e rimada."

Pesquisadores como Suavé, Gouveia e Pereira (2008), defendem a necessidade de renovação dos padrões de ensino. Também Freire (2019) abre um leque de possibilidades para o docente, e neste caso, para o professor de ER, ensinar de maneira lúdica, criativa, envolvente. Na pesquisa se percebe na fala dos entrevistados que a literatura de cordel dá ênfase ao ensino e 
a uma aprendizagem que englobe, além dos conhecimentos necessários, as habilidades, competências, análise e desenvolvimento de valores (MASETTO, 2003). Fazenda (1994) contribui com o que revela os professores pesquisados ao afirmar que a interdisciplinaridade possui a aptidão de alastrar os horizontes da sala de aula. Ela exige uma reflexão profunda e inovadora sobre o conhecimento, que demonstra a insatisfação com o saber fragmentado. Trazendo à prática docente a reflexão sobre a estrutura do conhecimento, para que assim possa superar a forma de ensino tradicional (JAPIASSU, 1976).

O uso de materialidades estéticas e ludoterápicas como estratégias facilitadoras da transmissão do conhecimento ainda é incipiente em nosso contexto escolar, havendo predomínio do emprego de modelos hegemônicos e tradicionalistas. Marinho e Pinheiro (2012), Curran (1998) e tantos outros autores defendem uma partilha de conhecimentos por meio da fantasia, como diversão, algo que seja prazeroso para o estudante se empolgar. Fazendo a opção pela literatura de cordel na escola, como aponta a pesquisa, o professor de ER faz uma escolha que instiga o discente a se envolver com algo mais atrativo, diferente, inclusive que pode interagir no smartfone e contribui para uma aprendizagem significativa, envolvente e interdisciplinar.

A utilização da literatura de cordel como método pedagógico de ensino propõe o despertar do senso crítico (SANTOS, 2020) capacidade de observação da realidade social, histórica, religiosa, política e econômica (ALVES, 2008). É nesse cenário que o trabalho com essa literatura, torna-se valioso, na medida em que propõe temas pertinentes ao coletivo, dando ênfase tanto à riqueza, quanto à expressividade da nossa cultura, rompendo os limites dos muros das salas de aula e possibilitando um trabalho norteado pelos princípios da interdisciplinaridade.

Vê-se que atualmente é grande a indicação do cordel como recurso pedagógico, como podemos perceber no discurso assertivo da entrevistada número 7

Como gostava de trabalhar com dinâmica, sempre trabalhei com músicas; vídeos e produções de textos envolvendo a diversidade cultural religiosa. Aproveitava também para fazer e criar com as/os estudantes paródias sobre essas temáticas. Essas aulas oferecem ao docente e discente uma gama de possibilidades de criar e inovar o processo de ensino e aprendizagem.

A maioria dos entrevistados pela pesquisa concordam que a utilização do cordel é eficaz na sala de aula, apenas dois professores ainda não demonstram ressalvas, como podemos perceber na seguinte fala, "Nunca usei e não penso em usar o cordel em sala de aula, primeiramente por falta de recurso didático e depois porque não saberia como utilizar, acho desnecessário." Vale salientar que diversos autores como Marinho e Pinheiro (2012); Oliveira e 
Rebouças (2008) apresentam dicas e sugestões para o uso desta literatura como ferramenta alternativa de comunicação, transmissão de conhecimento e interdisciplinaridade.

As Ciências das Religiões possibilitam um olhar para a compreensão do fenômeno religioso. Torres (2014) traz em seu trabalho o diálogo entre Ensino Religioso e Literatura, como exercício da interdisciplinaridade, possibilitando novas abordagens para o conhecimento dentro de outras investidas. De fato, estudos de críticas literárias e de literatura têm contribuído com pesquisas sobre diferentes possibilidades do fenômeno religioso.

Os professores pesquisados veem no cordel um leque de opções para instigar o estudante a viajar no conhecimento, na imaginação e na criatividade para navegar nas diversidades religiosas e culturais, nos direitos humanos, na cultura de paz, no respeito pelo diferente e pelas diferenças, na solidariedade, no compromisso para com a cidadania e na defesa dos Objetivos do Desenvolvimento Sustentável (ODS).

A interação entre ER e Literatura, como exercício da interdisciplinaridade, se dá porque toda produção literária está inserida dentro de um contexto histórico-cultural marcado pela religião. Na afluência entre Literatura e Ensino Religioso localizam-se alguns temas abordados pelos dois campos, tais como: Religiosidade, manifestação da crença de um povo, identidade social, síntese entre imanência e transcendência, virtudes espirituais, diversidade étnicas, imaginário religioso, ritos e mitos, entre tantos outros.

Corroborando com a teoria, cinco professores retificaram a possível contribuição entre literatura de cordel e o ensino religioso como podemos perceber na fala do entrevistado número 1:

Esta é uma forma de desenvolver as habilidades enriquecendo as aulas de Ensino Religioso e ao mesmo tempo motivando os discentes a construírem o conhecimento, interagindo e dialogando uns com os outros. Vocês já imaginaram a riqueza dessas aulas? A riqueza de aprendizagem!

Devido a característica legítima da pluralidade e diversidade há uma significativa riqueza de material disponível no intercâmbio entre literatura de cordel e ensino religioso. A linguagem literária atualiza, concretiza e interpreta as formas próprias das verdades do discurso religioso, coerente com o aspecto popular de uma literatura feita do povo e voltada para o povo (ARAÚJO, 2007), sobre a espontaneidade do relato sobre o comportamento da população sobre vários aspectos da vida. 


\section{Considerações finais}

Tanto a literatura sobre cordel, como os resultados que acabam de ser discutidos mostram o constante desenvolvimento de novas tecnologias de instrumentalização no processo de ensinoaprendizagem no ER, assim como possíveis transformações na dinâmica das Ciências das Religiões, emprestando novos significados a antigos processos.

Conclui-se que o uso do cordel mostrou-se um experimento pedagógico que estimula a criatividade no processo de ER, com baixo custo e de grande legado da tradição popular/cultural nordestina, propiciando aprendizado lúdico, criativo, prazeroso e contextualizado. O professor tem no cordel uma alternativa pedagógica eficaz, para utilizá-la na sua atuação profissional e, consequentemente, na melhoria da sua prática pedagógica.

Os professores utilizando o cordel, enxergam para além da ampliação do repertório artístico-cultural, as particularidades regionais, o exercício da escrita, vivências estéticas, produções e leituras de imagens, dentre outros aspectos benéficos. Podemos ainda destacar com o uso dessa literatura como constituinte de patrimônio de experiências sociais, religiosas e culturais, o oferecimento de excelentes contribuições para serem trabalhadas no ER, tais como no diálogo com os outros saberes do cotidiano social e popular, auxiliando o estudo das identidades e alteridades, das manifestações religiosas, das crenças religiosas e filosofias de vida, bem como nas habilidades e competências do Ensino Religioso com as demais áreas de conhecimento.

A pesquisa comprova que o conhecimento dos docentes sobre a literatura de cordel, encontra na interdisciplinaridade a possibilidade de integração dos conhecimentos das Ciências das Religiões e das aprendizagens do ER, numa teia onde a vida é soberana e a escola um espaço de convivência das diversidades, da solidariedade, da construção do bem comum, da cultura de paz, das superações das fragmentações, das indiferenças, das perversidades etc. A literatura de Cordel na sala de aula é uma oportunidade para despertar talentos, criar um clima de empatia, despertar humor e gratuidade, possibilitar experiências incríveis, quer seja de diversidades religiosas e/ou culturais, no apreço pelas diferenças e pelo diferente, por um oceano prazeroso e envolvente, com poesia, criatividade, alegria e sagacidade.

\section{REFERÊNCIAS}

ABREU, Márcia. Histórias de cordéis e folhetos. São Paulo: Ed. Mercado de Letras, 2009.

ALVES, Roberto Monteiro. Literatura de Cordel: por que e para que trabalhar em sala de aula. 
Revista Fórum Identidades, Sergipe, v. 4, n. 2, p. 103-109, jul./dez. 2008.

AMARAL, Daniela Patti do; OLIVEIRA, Renato José de; SOUZA, Evelin Christine Fonseca de. Argumentos para a formação do professor de ensino religioso no projeto pedagógico do curso de Ciências das Religiões da UFPB: que docente se pretende formar? Revista Brasileira de Estudos Pedagógicos, Brasília, v. 98, n. 249, p. 270-292, maio/ago. 2017.

ARAÚJO, Alceu Mayard. Cultura popular brasileira. São Paulo: Ed. Martins Fontes, 2007.

BARDIN, Laurence. Análise de Conteúdo. São Paulo: Ed. Edições 70, 2020.

BELISARIO, Danielle Dos Santos Souza; ALBUQUERQUE, Maria Elizabeth Baltar Carneiro de. Impacto do projeto "Cordel no espaço escolar" nas bibliotecas escolares de João Pessoa-PB. Informação \& Informação, Londrina, v. 20, n. 1, p. 250-278, jan./abr. 2015.

BORDENAVE, Juan Díaz; PEREIRA, Adair Martins. Estratégias ensino-aprendizagem. Petrópolis: Ed. Vozes, 2007.

BRASIL. Parecer CNE/CEB No: 8/2019. Altera o artigo 15 da Resolução CNE/CEB no 7, de 14 de dezembro de 2010, que fixa Diretrizes Curriculares Nacionais para o Ensino Fundamental de 9 (nove) anos. Disponível em: http://portal.mec.gov.br/index.php? option $=$ com_docman\&view $=$ download \&alias=138411-pceb008-19\&category _slug=janeiro2020\&Itemid=30192. Acesso em: 29 nov. 2019.

BRASIL. MEC. Base Nacional Comum Curricular. BNCC. Brasília/DF, 2017. Disponível em: http://basenacionalcomum.mec.gov.br/images/BNCC_EI_EF 110518 versaofinal_site. pdf. Acesso em: 29 nov. 2019.

BRASIL. Resolução CNE/CEB no 7, de 14 de dezembro de 2010. Fixa Diretrizes Curriculares Nacionais para o Ensino Fundamental de 9 (nove) anos. Brasília/DF, 2010. Disponível em: http://portal.mec.gov.br/dmdocuments/rceb007_10.pdf. Acesso em: 19 mar. 2020.

BRASIL. MEC. Nova redação do Art. 33 da Lei 9394/96. Lei no. 9475/97, de 22 de julho de 1997. Brasília: Diário Oficial da União, de 23 de julho de 1997, Seção I. Brasília/DF.

Disponível em: https://www2.camara.leg.br/legin/fed/lei/1997/lei-9475-22-julho-1997-365391publicacaooriginal-1-pl.html. Acesso em: $01 \mathrm{dez} .2019$.

BRASIL. MEC. Lei de Diretrizes e Bases da Educação Nacional Lei n. 9394/96, de 20 de dez. 1996. Diário Oficial da União, no 248 de 23. 12. 1996. Seção I. Brasília/DF. Disponível em: http://portal.mec.gov.br/seesp/arquivos/pdf/lei9394_ldbn1.pdf. Acesso em: 22 nov. 2019.

CARON, Lurdes (org.). O ensino religioso na nova LDB: histórico exigências e documentários. Petrópolis: Vozes, 1998.

CASTRO, Manoel Cavalcante de Souza; COSTA, Iris do Céu Clara. A literatura de cordel como instrumento didático-pedagógico na educação, motivação e promoção da saúde bucal.

Revista Ciência Plural, Rio Grande do Norte, v. 1, n. 1, p. 40-49, jan./abr. 2015. 
COBIAN, Marcella Braga; COSTA, Mariana Fernandes de Lima; PINTO, Maria Isaura Rodrigues. Trabalhando com literatura de cordel no ensino fundamental: relato de uma vivencia. Soletras, São Gonçalo, n. 21, p. 110-116, jan./jun. 2011.

COSTA, Ítalo Vidal Felix da. A Literatura de Cordel no Cotidiano Escolar. 2017. Trabalho de Conclusão de Curso (Graduação em Letras) - Curso de Letras, Universidade Estadual da Paraíba, Guarabira, 2017.

CURRAN, Mark. História do Brasil em Cordel. São Paulo: Ed. Editora da Universidade de São Paulo, 1998.

DIÉGUES JÚNIOR, Manuel. Literatura de Cordel. Maceió: Ed. Cadernos Folclore, 1975.

FAZENDA, Ivani Catarina Arantes. Interdisciplinaridade: História, teoria e pesquisa.

Campinas: Papirus Editora, 1994.

FIGUEIREDO, Maria Fernanda Santos; RODRIGUES-NETO, João Felício; LEITE, Maísa Tavares Souza. Modelos aplicados às atividades de educação em saúde. Revista Brasileira de Enfermagem, Brasília, v. 63, n. 1, p. 117-121, jan./fev. 2010.

FONSECA, Alexandre Vitor de Lima; FONSÊCA, Karen Sheron Bezerra. Contribuições da literatura de cordel para o ensino de cartografia. Geografia, Londrina, v. 17, n. 2, p. 123-132, jul./set. 2008.

FREIRE, Paulo. Pedagogia do oprimido. Rio de Janeiro: Paz e Terra, 2020.

FREIRE, Paulo. Pedagogia da Autonomia: saberes necessários a prática educativa. Rio de Janeiro: Paz e Terra, 2019.

FREITAS, Eliane Maura Littig Milhomem de. Bem-me-quer, Malmequer: um estudo sobre a presença do ensino religioso na Base Nacional Comum Curricular. 2018. $237 \mathrm{f}$. Tese (Doutorado em Ciência da Religião) - Curso de Pós-Graduação em Ciência da Religião, Pontifícia Universidade Católica de São Paulo, São Paulo, 2018.

HEINICH, Nathalie. La fabrique du patrimoine: de la cathédrale à la petite cuillère. Paris: Ed. Éditions de la Maison des Sciences de l'Homme, 2009.

HAURÉLIO, Marco. Breve história da literatura de cordel. São Paulo: Ed. Claridade, 2010.

HOLMES, Maria José Torres. Ensino Religioso: Esperanças e Desafios. Florianópolis: Ed. Saberes, 2016.

JAPIASSU, Hilton. Interdisciplinaridade e patologia do saber. Rio de Janeiro: Ed. Imago, 1976.

JUNQUEIRA, Sérgio Rogério Azevedo. O processo de escolarização do ensino religioso no Brasil. Petrópolis: Ed. Vozes, 2002.

LACERDA, Franciane Gama; MENEZES NETO, Geraldo Magella. Ensino e Pesquisa em História: a literatura de cordel na sala de aula. Revista Outros Tempos, Maranhão, v. 7, n. 72, p. 217-236, dez. 2010. 
MARIANO, Ricardo. Secularização do Estado, liberdades e pluralismo religioso. In: Civitas, Porto Alegre, v. 3, n. 1, p. 111-125, jun. 2003.

MARINHO, Ana Cristina; PINHEIRO, Hélder. O Cordel no cotidiano escolar. São Paulo: Ed. Cortez, 2012.

MASETTO, Marcos Tarcísio. Competências pedagógicas do professor universitário. São Paulo: Ed. Summus, 2003.

MAXADO, Franklin. O que é literatura de cordel? Rio de Janeiro: Ed. Codecri, 1980.

MENESES, Ulpiano T. Bezerra. A literatura de cordel como patrimônio cultural. Revista do Instituto de Estudos Brasileiros, São Paulo, n. 72, p. 225-244, abr. 2019.

MORAN, José Manuel. Ensino e aprendizagem inovadores com tecnologias. Informática na educação: teoria \& prática, Porto Alegre, v. 3, n. 1, p. 137-144, set. 2000.

MOREIRA, Valdecira Aparecida da Silva et al. Literatura de cordel x mídia na alfabetização e a motivação do gestor escolar. Tecnia, Goiânia, v. 4, n. 1, p. 91-107, jan./jun. 2019.

MORIN, Edgar. A cabeça bem feita: repensar a reforma, reformar o pensamento. Rio de Janeiro: Ed. Bertrand Brasil, 2002.

NOGUEIRA, Antonio Gilberto Ramos. Literatura de cordel: folclore, coleção e patrimônio imaterial. Revista do Instituto de Estudos Brasileiros, Brasil, n. 72, p. 262-275, abr. 2019.

OLIVEIRA, Jane Cristina et al. O Ensino Religioso nas escolas públicas do estado do Amapá: orientações curriculares e expectativas de aprendizagem. Revista Arquivos Científicos (IMMES), Macapá, v. 2, n. 1, p. 33-42, dez. 2019.

OLIVEIRA, Lilian Blanck de. A formação de docentes para o ensino religioso no Brasil: leituras e tessituras. Revista Diálogo Educacional, Curitiba, v. 5, n. 16, p. 247-267, set./dez. 2005.

OLIVEIRA, Paula Marciana Pinheiro; REBOUÇAS, Cristiana Brasil de Almeida; PAGLIUCA, Lorita Marlena Freitag. Literatura de cordel como meio de promoção para o aleitamento materno. Escola Anna Nery Revista de Enfermagem, Rio de Janeiro, v. 12, n. 2, p. 217-223, jun. 2008.

PARAIIBA. Proposta Curricular do Estado da Paraíba Educação Infantil e Ensino Fundamental. Secretaria de Estado da Educação e da Ciência e Tecnologia da Paraíba, Paraíba. p. 368. 2019. Disponível em: https://pt.scribd.com/document/400257668/PropostaCurricular-Do-Estado-Da-Paraiba-Educacao-Infantil-e-Ensino-Fundamental. Acesso em: 28 dez. 2019.

PEIXOTO, Mariana do Carmo de Almeida. Literatura de cordel: da oralidade à escrita. 2003. Trabalho de Conclusão de Curso (Graduação em Biblioteconomia e Documentação) - Curso em Biblioteconomia e Documentação, Instituto de Arte e Comunicação Social, Universidade Federal Fluminense, Niterói, 2003. 
PEREIRA, Lívia Maria Galdino et al. O cordel no ensino de microbiologia: a cultura popular como ferramenta pedagógica no ensino superior. Revista Eletrônica de Comunicação, Informação e Inovação em Saúde, Rio de Janeiro, v. 8, n. 4, p. 512-524, out./dez. 2014.

PUHL, Paula Regina; LOPES, Poliana. Cordel Encantado: a telenovela encantada com a literatura popular. Comunicação Mídia e Consumo, São Paulo, v. 8, n. 22, p. 35-63, jul. 2011.

RANQUETAT JUNIOR, Cesar A. Religião em sala de aula: o ensino religioso nas escolas públicas brasileiras. CSOnline-Revista Eletrônica de Ciências Sociais, Juiz de Fora, p. 163180, fev. 2007.

RIBEIRO, Maria Luísa S. História da educação brasileira: a organização escolar. São Paulo: Ed. Moraes, 1982.

RODRIGUES, Anderson Favero. Cordel, Fantasia e Poesia: Uma viagem mestiço-mediática no Desfile do Salgueiro. 2013. Dissertação (Mestrado em Comunicação e Cultura) Universidade de Sorocaba, Sorocaba, 2013.

SANTOS, Tália de Azevedo Souto. Laicidade do Estado e Ensino Religioso no Brasil: Trajetórias, desafios e perspectivas. 2019. 126 f. il. Dissertação (Mestrado em Direitos Humanos, Cidadania e Políticas Públicas) - Universidade Federal da Paraíba, João Pessoa, 2019.

SANTOS, Mirinalda Alves Rodrigues dos. Ensino Religioso e Currículo: sentidos, implicações e ressignificações nos cursos de Ciências das Religiões. 2020. 295 f. Tese (Doutorado em Ciências das Religiões) - Universidade Federal da Paraíba, João Pessoa, 2020.

SAUVÉ, Jean Philippe Guimarães; GOUVEIA, Zoraida Maria de Medeiros; PEREIRA, Marsílvio Gonçalves. Biologia experimental em escolas públicas: trabalhando no Lyceu Paraibano. Centro de Ciências Exatas e da Natureza/ Departamento de Sistemática de Ecologia/ PROLICEN. Rio de Janeiro. 2008. Disponível em:

http://www.prac.ufpb.br/anais/xenex_xienid/xi_enid/prolicen/ANAIS/Area4/4CCENDSEPLIC 03.pdf. Acesso em: 21 mar. 2020.

SILVA, Verônica Diniz da. A Literatura de Cordel e suas contribuições para o ensino desse gênero na sala de aula. In: Simpósio Linguagens e Identidades da/na Amazônia Sul-Ocidental, 10., 2016, Rio Branco. Anais [...]. Rio Branco: Universidade Federal do Acre, 2016.

Disponível em: https://periodicos.ufac.br/index.php/simposioufac/article/view/831. Acesso em: 21 abr. 2020.

SILVA FILHO, Wilson Seraine da. O uso da Literatura de Cordel como texto auxiliar no Ensino de Ciências do Ensino Fundamental da Educação Básica: Uma abordagem quantitativa. 2009. Dissertação (Mestrado em Ensino de Ciências e Matemática) -Universidade Luterana do Brasil, Canoas-RS, 2009.

SILVA, Míriam Cristina Carlos; GABRIEL, Gisele. Literatura de cordel e narrativas ambientais. Revista Internacional de Folkcomunicação, Ponta Grossa, v. 17, n. 38, p. 217233, jan./jun. 2019. 
SILVA, Silvio Profirio et al. Literatura de Cordel: Linguagem, comunicação, cultura, memória e interdisciplinaridade. Revista Raído, Dourados, v. 4, n. 7, p. 303-322, jan./jun. 2010.

SOUZA, Aline Macedo; FRANCISCO, Odair Benedito. Contação de histórias: um recurso pedagógico no desenvolvimento da linguagem. Colloquium Humanarum, Presidente Prudente, v. 14, n. 1, p. 40-51, jan./ mar. 2017.

STACCIARINI, Jeanne Marie R.; ESPERIDIÃO, Elizabeth. Repensando estratégias de ensino no processo de aprendizagem. Revista Latino-am Enfermagem, Ribeirão Preto, v. 7, n. 5, p. 59-66, dez, 1999.

TORRES, Maria Augusta de Sousa. Um olhar sobre o ensino religioso e a literatura em "Morte e Vida Severina". Revista de Teologia e Ciências da Religião da UNICAP, Recife, v. 4, n. 1, p. 7-28, dez. 2014.

\section{SOBRE OS AUTORES:}

\section{Paula Marques Pessoa de Aquino}

Mestranda do Programa de Pós-Graduação em Ciências das Religiões, da Universidade Federal da Paraíba. Membro do Laboratório de Pesquisa em Logoterapia e Análise Existencial de Pesquisa (LAPPLAE). Bolsista da CAPES. E-mail: paulamlpda@ hotmail.com

(iD https://orcid.org/0000-0002-0783-1291

\section{Vitória da Cunha Ferreira}

Mestranda do Programa de Pós-Graduação em Ciências das Religiões, da Universidade Federal da Paraíba. Membro do Laboratório de Pesquisa em Logoterapia e Análise Existencial de Pesquisa (LAPPLAE). Bolsista da CAPES. E-mail: vitoriapsi96@ gmail.com.

iD https://orcid.org/0000-0001-7506-7451

\section{Lusival Antonio Barcellos}

Doutor em Educação pela Universidade Federal do Rio Grande do Norte. Professor Associado do Departamento e do Programa de Pós-Graduação em Ciências das Religiões, da Universidade Federal da Paraíba. Membro do Grupo de Pesquisa Estudos em intolerância, Diversidade e Imaginário (VIDELICET). E-mail: lusival.barcellos@academico.ufpb.br

(iD https://orcid.org/0000-0002-3482-0221

Recebido em: 02 de maio de 2020

Aprovado em: 13 de agosto de 2020 Publicado em: 01 de dezembro de 2020 